\section{Bulb Quality and Traumatic Acid Influence Bulblet Formation from Scaling in Lilium Species and Hybrids}

\author{
Pablo Marinangeli and Néstor Curvetto \\ Departamento de Agronomía, Universidad Nacional del Sur, San Andrés 800, \\ 8000 Bahía Blanca, Argentine
}

Additional index words. Lilium longiflorum, Lilium lancifolium, oriental hybrid, asiatic hybrid, lily

\begin{abstract}
Scaling is a common commercial technique to propagate Lilium. The present research work evaluated the impact of genotype, traumatic acid (TA), and initial bulb quality on bulblet production by scaling propagation. Genotypes used were: L. longiflorum Thunb. 'Snow Queen', L. lancifolium Thunb., one Oriental hybrid ( $L . x$ 'Stargazer'), and four Asiatic hybrids ( $L . x$ 'Enchantment', $L . x$ 'Connecticut King', $L . x$ 'Sunray', L.x 'Cote d'Azur'). The genotypes showed a wide variability in the number (1.1-2.6 bulblets per scale) and biomass (83-295 mg per bulblet) of bulblet production. The same variability was exhibited after treatment with TA, which produced an increase of $20 \%$ to $40 \%$ in the number of bulblets per scale and also a significant increase in their fresh mass $(20 \%$ to $60 \%$ ). Using poor quality $L . \times$ 'Cote d'Azur' bulbs adversely affected the biomass and number of bulblets produced on the scales, and this effect was not overcome with TA treatment. Chemical name used: 10(E) dodeca-1,12-dicarboxylic acid (traumatic acid).
\end{abstract}

Scaling is the most widely used commercial method of Lilium propagation. Healthy bulb scales are separated from the bulb basal plate and kept in moist peat, $\mathrm{pH} 6.0$ at ca. 25 ${ }^{\circ} \mathrm{C}$, until one or more adventitious bulblets differentiate at the scale base after 2 to 3 months. The magnitude of the response (number of bulblets per scale) depends on intrinsic factors such as cultivar, size, age, physiological and sanitary status of the bulb, position of the scale in the bulb, and on abiotic factors, such as temperature, humidity, light irradiance, and any physical or chemical treatment. All these factors affect bulb survival and bulblet production (Grassotti and Magnani, 1988; Magnani et al., 1988, 1990; Matsuo et al., 1987). However, among these, the species or cultivars used for propagation is the most important factor. In fact, the multiplication potential of plant material from differing genetic sources is highly variable, even in the micropropagation method where most factors may be adequately controlled (Panizza et al., 1990; Takayama and Misawa, 1979). Thus, differences of $0 \%$ to $100 \%$ in the multiplication rate among cultivars have been observed (Magnani et al., 1990; Malorgio et al., 1988).

The physiological status of the starting bulbs is of the utmost importance in the magnitude of the propagation rate and also in the bulblet final biomass, since both directly depend on the level of food storage in the bulbs.

Received for publication 18 June 1996. Accepted for publication 19 Nov. 1996. We thank Ing. Silvia Delmastro for technical assistance and Luis Hernandez and Levan Darjania for critical reading of the manuscript. The cost of publishing this paper was defrayed in part by the payment of page charges. Under postal regulations, this paper therefore must be hereby marked advertisement solely to indicate this fact.
During storage and handling, the parental material often loses water and food reserves, both acting negatively on the multiplication phase.

Traumatic acid has been reported to play a hormonal role in wounded plant tissue. This dicarboxylic acid was isolated from the mesocarp of wounded beans (Phaseolus vulgaris L.) and was shown to enhance cell proliferation at the wound site (English et al., 1939). The traumatic acid they originally identified likely arose through the oxidation of an unstable alkenal, traumatin, 12-oxo-10(E)dodecenoic acid, with a putative higher biological activity (Zimmerman and Coudron, 1979). The dicarboxylic acid is the chemical form commercially available, and the one usually employed (Farmer, 1994).

The influence of TA on various in vitrocultured tissues has been reported (Marinangeli et al., 1995). In vitro formation of adventitious buds in Brassica oleracea L. var. botrytis was stimulated by TA (Margara, 1977). In Torenia fournieri Lindl. (Tanimoto and Harada, 1984) and Lilium longiflorum Thunb. (Ishioka and Tanimoto, 1990), the exposed culture area of the explant and incubation with TA, within the first hour of explant extraction, were important factors in the improvement of in vitro bulblet differentiation.

These results constitute indirect evidence of the involvement of TA as an inducer of the on number of bulblets per scale and fresh mass of bulblets.

;,**Significant at $P \leq 0.05$ or 0.01 , respectively. formation of adventitious organs, by influencing cellular division and differentiation (Ishioka and Tanimoto, 1990; Marinangeli et al., 1995). However, the organogenic effect that TA may exert on in vivo-propagated Lilium plants has not been evaluated. The objective of this work was to evaluate whether or not genotype, initial bulb quality, and TA treatment of bulb scales affected bulblet production by scaling propagation.

\section{Materials and Methods}

The Lilium species and hybrids L. longiflorum 'Snow Queen', L. lancifolium, an Oriental hybrid ( $L$. X 'Star Gazer'), and four Asiatic hybrids ( $L . \mathrm{x}$ 'Enchantment', L. X 'Connecticut King', L. x 'Sunray', L. x 'Cote d'Azur') were evaluated for bulblet formation during scaling propagation. Parental bulbs were grown in the Ventania Sierras (Buenos Aires province, Argentine), harvested at the end of summer, and stored for 2 months at $4{ }^{\circ} \mathrm{C}$ prior to experimental work. The bulbs chosen were from 14 to $16 \mathrm{~cm}$ in diameter. In addition, the Asiatic hybrid $L . \times$ 'Cote d'Azur' was also obtained at a local plant store.

Sorting of bulbs as "good" or "poor" was done on the basis of their water content by difference between fresh and dry mass, and their appearance.

External and middle scales were removed from the bulbs and the external ones were discarded. The middle scales were washed with tap water and disinfected by immersion for 20 min in a sodium hypochloride solution ( $2 \%$ active chlorine), containing two drops of the surfactant Tween $20 / \mathrm{L}$, followed by treatment for $30 \mathrm{~min}$ with a solution consisting of $0.1 \%$ (w/v) Benomil (Benlate PM 50\%, w/w, methyl 1-butylcarbamoyl-2-benzymidazol carbamate) and $0.03 \%(\mathrm{w} / \mathrm{v})$ streptomycin sulfate. To provide adequate support and conditions for the incubation of the scales, a quantity of peat (sphagnum moss) was prepared by correcting the $\mathrm{pH}$ to $6.0-6.5$ by addition of $5 \%(\mathrm{w} / \mathrm{w}) \mathrm{CaCO}_{3}$ and by watering to obtain a $6: 4(\mathrm{v} / \mathrm{w})$ water to peat ratio. This medium was sterilized in an autoclave at 121 ${ }^{\circ} \mathrm{C}$ for $3 \mathrm{~h}$. Final water to peat ratio was $4: 1$ (w/ w). Finally, the scales were placed in perforated 1-L polyethylene bags and kept in darkness for 2 months at $25 \pm 2{ }^{\circ} \mathrm{C}$. The softly packed peat, together with the holes made in the bags, permitted an adequate aeration. The ratio of scales to peat was $4: 6(\mathrm{w} / \mathrm{w})$. Water content in the bags was controlled weekly and maintained to the above-mentioned value.

Traumatic acid (Sigma Chemical Co., St. Louis) was dissolved using an aliquot of ethanol; then water was added to achieve a $100 \mathrm{~mm}$

Table 1. Analysis of variance table for the effect of Lilium genotype, traumatic acid, and their interaction

\begin{tabular}{lccrrr}
\hline & \multicolumn{2}{c}{ Bulblets/scale } & & \multicolumn{2}{c}{ Fresh mass/bulblet } \\
\cline { 2 - 3 } Variable & F value & Significance & & F value & Significance \\
\hline Species and hybrids (SH) & 69.2767 & $* *$ & & 30.1862 & $* *$ \\
Traumatic acid (TA) & 71.7066 & $* *$ & & 63.7786 & $* *$ \\
SH $\times$ TA & 2.3156 & $*$ & & 2.5531 & $*$ \\
\hline
\end{tabular}


Table 2. Effect of traumatic acid (TA) on the number of bulblets per scale and fresh weight per bulblet for several Lilium genotypes.

\begin{tabular}{|c|c|c|c|c|c|c|}
\hline \multirow[b]{2}{*}{ Lilium genotype } & \multicolumn{3}{|c|}{ Bulblets/scale } & \multicolumn{3}{|c|}{ Fresh mass/bulblet (mg) } \\
\hline & $-\mathrm{TA}$ & $+\mathrm{TA}$ & $\overline{\text { Significance }}$ & $-\mathrm{TA}$ & $+\mathrm{TA}$ & Significance \\
\hline L. longiflorum & $1.5 \mathrm{~b}^{\mathrm{z}}$ & $2.0 \mathrm{bc}$ & $* *$ & $127 \mathrm{~b}$ & $251 \mathrm{~b}$ & $* *$ \\
\hline L. lancifolium & $2.2 \mathrm{~cd}$ & $3.1 \mathrm{~d}$ & $* *$ & $136 \mathrm{~b}$ & $230 \mathrm{~b}$ & $* *$ \\
\hline L. x 'Stargazer' & $1.3 \mathrm{ab}$ & $1.7 \mathrm{~b}$ & $*$ & $216 \mathrm{c}$ & $262 b$ & $* *$ \\
\hline L. X 'Enchantment' & $1.1 \mathrm{a}$ & $1.2 \mathrm{a}$ & $* *$ & $83 a$ & $144 \mathrm{a}$ & $* * 2$ \\
\hline L. X 'Connecticut King' & $2.5 \mathrm{~d}$ & $3.2 \mathrm{~d}$ & $* *$ & $172 \mathrm{c}$ & $206 \mathrm{~b}$ & NS \\
\hline L. X 'Sunray' & $2.6 \mathrm{~d}$ & $3.4 \mathrm{~d}$ & $*$ & $225 \mathrm{c}$ & $367 \mathrm{c}$ & $*$ \\
\hline L. X 'Cote d'Azur' & $2.0 \mathrm{c}$ & $2.4 \mathrm{c}$ & $* *$ & $295 \mathrm{~d}$ & $346 \mathrm{c}$ & $* *$ \\
\hline
\end{tabular}

${ }^{\mathrm{z}}$ Genotypes mean separation within columns using Fisher's protected LSD at $P \leq 0.05$.

ss, *, ** Nonsignificant or significant at $P \leq 0.05$ or 0.01 , respectively.

Table 3. Analysis of variance table for the effect of Lilium bulb quality, traumatic acid and their interaction on number of bulblets per scale and fresh mass of bulblets.

\begin{tabular}{lrrrrr}
\hline \hline & \multicolumn{2}{c}{ Bulblets/scale } & & \multicolumn{2}{c}{ Fresh mass/bulblet } \\
\cline { 2 - 3 } \cline { 5 - 6 } Variable & F value & Significance & & F value & Significance \\
\hline Bulb quality (BQ) & 38.2912 & $* *$ & & 107.2733 & $* *$ \\
Traumatic acid (TA) & 4.2546 & $*$ & & 4.7969 & $*$ \\
BQ $\times$ TA & 3.3124 & NS & & 1.8968 & NS \\
\hline
\end{tabular}

Ns,*,**Nonsignificant or significant at $P \leq 0.05$ or 0.01 , respectively.

TA concentration. To evaluate the effect of TA, half the scales were immersed in $1 \mu \mathrm{M}$ aqueous solution TA for $1 \mathrm{~h}$ before treating them with the fungicide and bactericide solution. Control scales were immersed in tap water for the same period.

A randomized design was applied for species and hybrids, bulb quality, and TA experiments. Each bag contained one treatment, which consisted of 43 middle scales. The number of bulblets produced per scale was counted. Fifty-three and 67 bulblets per treatment were weighed for the varietal/TA and bulbquality/TA experiments, respectively. The F-test for treatments was based on two-way analysis of variance (ANOVA) followed by Fisher's protected LSD test (Ott, 1984) at $P \leq$ 0.05 for Lilium species and hybrid bulblet yield and biomass comparisons. One-way ANOVA (Ott, 1984) was used to compare individual TA treatment effects in varietal/TA and bulb quality/TA experiments.

For Lilium x 'Cote d'Azur' bulb quality, water content was obtained from the difference between the fresh and dry mass of 20 middle scales of five bulbs of each quality and tested by one-way ANOVA. The design was a complete randomized block (Ott, 1984).

\section{Results and Discussion}

Genotype effect on bulblet differentiation yield and its interaction with traumatic acid. Genotype affected bulblet formation in Lilium (Table 1). Bulblets per scale ranged between 1.1 and 2.6 and between 83 and $295 \mathrm{mg}$ fresh mass (FM) per bulblet (Table 2). These differences, reflecting the genetic influence, were significant not only between the species or group of hybrids studied, but also among the group of Asiatic hybrids (Table 2). Our results are in good agreement with those obtained under similar conditions with 'Yellow Blaze', 'Connecticut King', 'Mont Blanc', and 'Enchantment' cultivars, all of them Asiatic hybrids (Magnani et al., 1988). The results also were similar with the same Asiatic hybrids, the cultivars Arai and Madonna belonging to $L$. longiflorum, and the Oriental hybrid 'Star Gazer' (Magnani et al., 1990). Moreover, Van Tuyl (1983) showed differences in the number of bulblets produced in $L . \mathrm{x}$ 'Enchantment' and L. longiflorum 'White Europe'.

Traumatic acid increased the number of bulblets per scale ( $20 \%$ to $40 \%$ ), while the increase in FM was between $20 \%$ to $60 \%$ (Table 2). The interaction between genetic and TA treatment effects was significant (Table 1). Three other Asiatic hybrids, L. X 'Corina', $L$. x 'Apeldoorn', and $L$. x 'Geneve', also increased in the number of bulblets per scale $(21 \%, 23 \%$, and $11 \%$, respectively) when treated with TA (results not shown).

The effect of TA was similar to the one exhibited on Lilium cv. Connecticut King (Asiatic hybrid) during in vitro propagation (Marinangeli et al., 1995). In fact, TA led to earlier differentiation of bulblets, a higher survival rate, and a marked increase in the number and biomass of bulblets (Marinangeli et al., 1995).

Traumatic acid enhances cell proliferation at the wound site (English et al., 1939) and induces the formation of adventitious organs by influencing cellular division and differentiation (Ishioka and Tanimoto, 1990; Marinangeli et al., 1995), but no clear working of its action is hitherto known. Since TA acts at the wound site, enhancing cell proliferation, and since bulblet differentiation occurs at this site, the wound-healing signal may stimulate differentiation of adventitious buds which, in turn, give rise to an increased number of bulblets. Narcissus tazetta L. did not respond to TA (unpublished results). In N. tazetta, cell differentiation does not occur at the wound site but on the axillary buds at the basal disk, where TA cannot exert its action.

Effect of the quality of source bulb on bulblet differentiation and its interaction with $T A$. Good quality and poor quality bulbs differed significantly $(P \leq 0.01)$ in water content $(65.6 \%$ vs. $50.5 \%)$. The former did not show sprouting and appeared turgid; those scored as "poor" showed external signs of dehydration and sprouting. Poor quality L.x 'Cote d'Azur' bulbs had a lower FM and produced fewer bulblets after scaling than did good quality bulbs (Tables 3 and 4). Almost 25\% more bulblets were differentiated from the "good" bulbs, whose FM increased $\approx 85 \%$, reaching an average $\mathrm{FM}$ of $\approx 300 \mathrm{mg}$ per bulblet.

No interaction was found between bulb quality and TA treatment either in bulblet yield per scale nor in FM (Table 3). Also, TA treatment was not useful in improving either the number of bulblets per scale or the biomass of "poor" bulbs, but it did produce a significant increase in these variables on "good" bulbs (Table 4). This average increase was $\approx 17 \%$ and $19 \%$ in bulblet biomass and bulblet yield per scale, respectively. Thus, TA exerts positive effects when good quality bulbs are used.

Our results provide practical information on the need to use good quality bulbs to assure a high lily multiplication rate. Also, TA can be incorporated in commercial bulb production to increase bulb yield at relatively low cost.

\section{Literature Cited}

English, J., J. Bonner, and J. Haagen Smit. 1939. The wound hormones of plants. II. The isolation of a crystalline active substance. Proc. Natl. Acad. Sci. USA 25:323-329.

Farmer, E.E. 1994. Fatty acid signalling in plants and their associated microorganisms. Plant Mol. Biol. 26:1423-1437.

Grassotti, A., and G. Magnani. 1988. Stato attuale e

Table 4. Influence of Lilium $\times$ 'Cote d'Azur' bulb quality and traumatic acid (TA) on the number of bulblets per scale and fresh mass per bulblet.

\begin{tabular}{lccccccc}
\hline \hline Bulb & Water & \multicolumn{3}{c}{ Bulblets/scale } & \multicolumn{3}{c}{ Fresh mass/bulblet (mg) } \\
\cline { 2 - 8 } quality & content $(\%)$ & - TA & +TA & Significance & -TA & Significance \\
\hline Good & 65.6 & 2.0 & 2.4 & $* *$ & 295 & 346 & 173 \\
Poor & 50.5 & 1.6 & 1.6 & NS & 163 & NS \\
\hline
\end{tabular}

Ns, ** Nonsignificant or significant at $P \leq 0.01$, respectively. 
prospettive della moltiplicazione in vivo de Lilium. Colture Protette 17:33-42.

Ishioka, N. and S. Tanimoto. 1990. Studies on bulblet differentiation in bulb-scale segments of Lilium longiflorum. I. Effects of wounding and traumatic acid. Bul. Fac. Agr., Saga Univ. 69:27-33.

Magnani, G., F. Malorgio, and B. Mori. 1990. Osservazioni e ricerche sulla moltiplicazione da scaglie del Lilium. Colture Protette 19:61-68.

Magnani, G., F. Malorgio, and E. Moschini. 1988 Influenza del livello termico in fase de moltiplicazione da scaglie sulla produzione $\mathrm{di}$ bulbetti di Lilium. Colture Protette 17:69-74.

Malorgio, F., G. Magnani, and E. Moschini. 1988. Propagazione in vivo di alcune cultivar di Lilium 'Mid Century'. L'Informatore Agrario 5:69-72.

Margara, J. 1977. Effets d'auxines et d'antiauxines sur la néoformation de bourgeouns in vitro chez le chou-fleur (Brassica oleracea L. var. botrytis). Comp. Rend. Acad. Sci. Paris Sér. D 284:1883-1885.

Marinangeli, P., R. Devalis, S. Delmastro, and N. Curvetto. 1995. Stimulation of bulblet differentiation by traumatic acid in Lilium bulb-scale segments cultured in vitro. Biocell 19:189-195

Matsuo, E., A. Nonaka, and K. Arisumi. 1987. Some factors influencing the type of leaf development (plant type) of scale bulblets of Easter Lily, Lilium longiflorum. Bull. Faculty Agr. Kagoshima Univ. 37.

Ott, L. 1984. An introduction to statistical methods and data analysis. 2nd ed. PWS Publishers, Boston.

Panizza, M., A. Mensuali Sodi, and F. Tognoni. 1990. Effects of various factors on in vitro propagation of Lilium speciosum Thunb. and
Liliumlongiflorum Thunb. Adv. Hort. Sci.4:103106.

Takayama, S. and M. Misawa. 1979. Differentiation in Lilium bulbscales grown in vitro. Effects of various cultural conditions. Physiol. Plant. 46:184-190.

Tanimoto, S. and H. Harada. 1984. Stimulation of adventitious bud initiation by cyclic AMP and traumatic acid in Torenia stem segments. Biol. Plant. 26:337-341.

Van Tuyl, J. 1983. Effect of temperature treatments on the scale propagation of Lilium longiflorum 'White Europe' and Lilium x 'Enchantment'. HortScience 18:754-756.

Zimmerman, D.C. and C.A. Coudron. 1979. Identification of traumatic, a wound hormone, as 12oxo-trans-10-dodecenoic acid. Plant Physiol. 63:536-541 